\title{
A Pesquisa em Artes Cênicas pelo Grupo Tercer Abstracto
}

\author{
Research In Performing Arts According To The Tercer Abstract Group
}

\author{
Rosyane Trotta \\ Universidade Federal do Estado do Rio de Janeiro - UNIRIO, Rio de Janeiro/RJ, Brasil \\ E-mail: rosyane.trotta@unirio.br
}

\section{Resumo}

O grupo chileno-brasileiro Tercer Abstracto, que atua desde 2012 e tem nove obras no curriculum, define o teatro que faz como "pesquisa em artes". Segundo sua página virtual, "a investigação guia a criação" e, nesse contexto, o processo "parte de uma pergunta, um problema". No dia 11 de maio de 2021, eles apresentaram sua metodologia de criação para os alunos da disciplina Laboratório de Encenação, ministrada na UNIRIO por Rosyane Trotta, e discutiram as relações entre arte e ciência na universidade. Aqui, trazemos uma síntese da entrevista, da qual participam também os alunos Grassi Santana e Carlos Estranho.
The Chilean-Brazilian group Tercer Abstracto, which has been operating since 2012 and has nine works on its curriculum, defines the theater they practice as "art research". According to its website, "the investigation guides the creation" and, in this context, the process "starts from a question, a problem". On May 11, 2021, they presented their creation methodology to students of the Staging Laboratory course, taught at UNIRIO by Rosyane Trotta, and discussed the relationship between art and science at the university. Here, we bring a summary of the interview, in which students Grassi Santana and Carlos Estranho also participate. Grupo. 
A inserção da área de Artes nas universidades, especificamente nos programas de pós-graduação stricto sensu (mestrados e doutorados), abriu uma discussão sobre a noção de pesquisa em artes que fomentou os debates acadêmicos de distintos países, desde o final dos anos 1990 (BORGDORFF, 2017). A pesquisadora chilena Maria José Contreras trata do conceito de pesquisa performativa no livro Cadáver Exquisito: tres experiencias de investigación performativa en Chile $(2020)^{1}$, em que aborda a relação entre teoria, prática e pesquisa no trabalho de três grupos teatrais. Entre eles, a companhia Tercer Abstracto surge com o objetivo de investigar princípios e procedimentos metodológicos para a elaboração de suas obras, a partir da friç̧ão entre teoria e prática. De caráter transdisciplinar, seu processo criativo associa arte e ciência, buscando levar ao público de teatro temas provenientes da física e das matemáticas, a partir do estímulo à percepção visual e sonora do espectador para criar novas linguagens de encenação. Tomei conhecimento de seu trabalho por ocasião da quarta edição do festival Crítica em Movimento onde, em abril de 2021, foi apresentado o espetáculo Épico, que explorava os recursos da plataforma de videoconferência em torno das proposições do teatro épico e cuja sinopse, por meio de perguntas, estabelecia uma relação entre a atual pandemia e a peste na Europa medieval ${ }^{2}$. Os integrantes Mateus Fávero, ator e dramaturgista, e David Atencio, diretor, são, respectivamente, mestrando e doutorando na Universidade de São Paulo, onde desenvolvem pesquisas artísticas em diálogo com o trabalho do grupo. Eles falam sobre essa prática que, pela elaboração de perguntas e busca de respostas cênicas, conduz a uma linguagem autoral e híbrida.

Rosyane Trotta: O que define a linguagem do Tercer Abstracto e norteia o trabalho do grupo?

1 Disponível em: https://www.researchgate.net/publication/348559103_Cadaver_Exquisito_tres_experiencias_de_investigacion_performativa_en_Chile. Ācesso em: 29 set. $202 \overline{1}$.

2 Ver https://www.itaucultural.org.br/secoes/agenda-cultural/critica-movimento-apresenta-espetaculos-podcast-especial\#programacao
David Atencio: Tercer Abstracto se define como uma companhia de pesquisa. Temos duas linhas de projeto. A Série Abstracto é o estudo de artistas visuais, principalmente da abstração. O Projeto Manifestos se desenvolve principalmente aqui no Brasil, pelo estudo dos encenadores da modernidade: a primeira peça foi Convenção, a partir de Meyerhold, e a segunda foi Épico, a partir de Brecht.

Figura 1 - S.U.B...C.E.R.O. (2014), a partir da arte abstrata do ucraniano Kazimir Malevich (18791935).

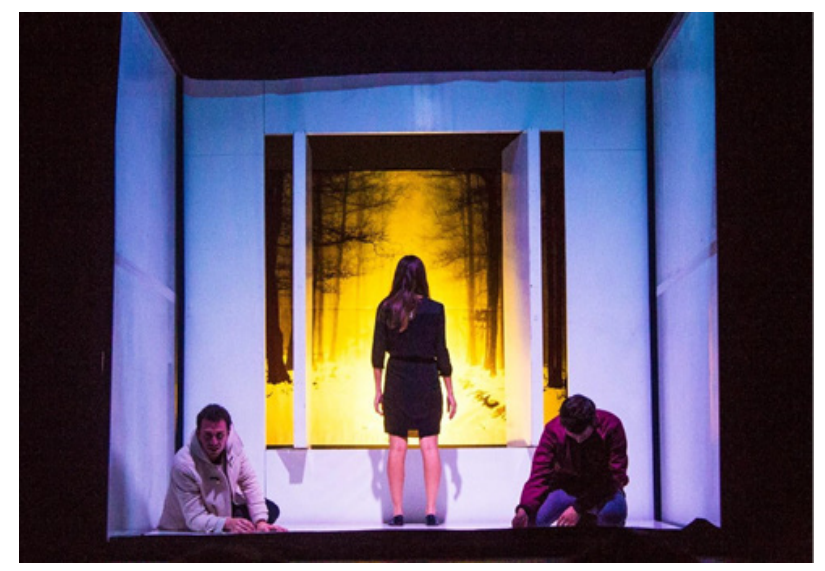

Fonte: S.U.B...C.E.R.O (2014). Foto de Andrea Vukusich (Acervo Tercer Abstracto)

Mateus Fávero: Na Série Abstracto, o processo de estudo sobre o pintor russo Vladimir Tatlin nos levou ao construtivismo, o construtivismo nos levou a Meyerhold e ao processo que resultou em Convenção. Assim surgiu a segunda linha de pesquisa dentro da companhia, o Projeto Manifestos.

David Atencio: Atualmente estudamos Schlemmer e o conceito sobre figura humana. A gente se interessa pelo senso político e estético que está por trás. O que a gente procura são as perguntas, não é o estilo ou a forma. A partir das perguntas começa o processo de "contemporaneização", em que a gente investiga como essa cena moderna pode existir hoje. 
Figura 2 - Figura Humana (2021) se baseia no manifesto "Homem e figura artística" (1925), escrito por Oskar Schlemmer.

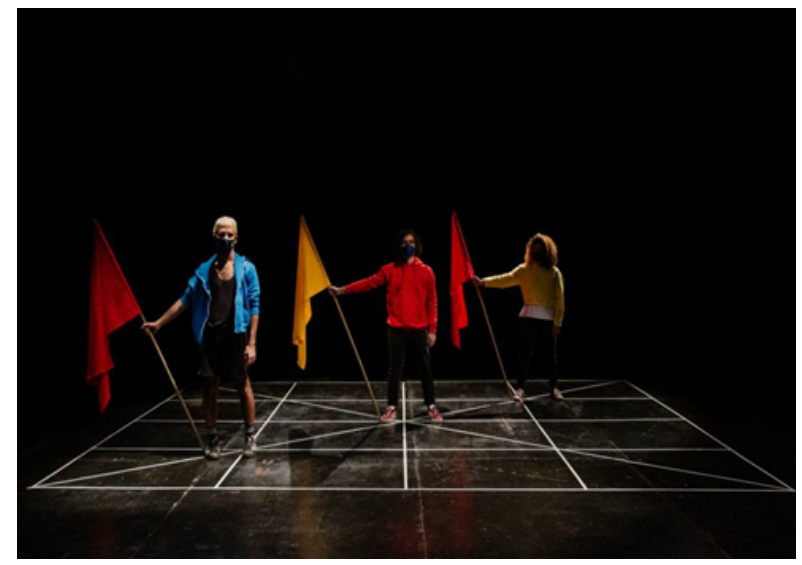

Fonte: Figura Humana (2021). Foto de Brendo Trolesi (Acervo Tercer Abstracto)

Rosyane Trotta: Como se chega a essas perguntas e como elas funcionam no processo?

Mateus Fávero: O processo parte de uma pergunta. Não parte de um interesse, de uma inspiração ou de um material base de que eu vou me apropriar. No caso de Épico, a gente escolheu O pequeno organon, de Brecht, como material fundamental de pesquisa e, olhando para aquele material, buscamos a pergunta de pesquisa, que vai guiar todo o processo de laboratório e as experimentações que são feitas até a conclusão, na formalização da peça. O que guia o processo, e é aquele lugar para onde a gente sempre volta quando se perde nesse processo de se perder durante o processo, é a pergunta de pesquisa.

David Atencio: A pergunta de pesquisa é fundamental. Na verdade, a gente não começa com a pergunta, a gente chega a uma pergunta. O processo começa com o estudo de um artista da modernidade, primeiro do ponto de vista histórico, depois com estudo teórico. Essa primeira fase, com toda a equipe, que chamamos de Estudo dos Materiais, termina com a formulação de uma pergunta. No caso do Épico, a pergunta foi: como estabelecer um contato dialético com o espectador através do teatro online? Essa formulação vai se modificando à medida que vamos praticando e construindo. A gente trabalha com uma lousa, escreve as perguntas, vai trabalhando isso de forma visual. Tentamos ser científicos, no sentido de não perder a linha de pesquisa. Se o estudo, o conhecimento, as referências, vão te levando para outro lugar, você verifica: "isso está respondendo à minha pergunta?"

Rosyane Trotta: Sem querer fechar uma metodologia, mas para verificar se entendemos bem: primeiro o estudo histórico, depois o estudo conceitual, em seguida a pergunta e só então a experimentação na sala de ensaio.

David Atencio: Sim.

Mateus Fávero: A gente não tem nenhum problema com a palavra método ou metodologia, só tenta não enxergar essa palavra como algo duro, que restrinja. $\mathrm{Na}$ verdade, falamos muito de metodologia. O mestrado do David é ao mesmo tempo uma peça, uma memória de peça e uma descrição de processo de criação - e nesse exercício de descrever o processo, ele cunha o termo "metodologia da abstração". Ela vem sendo reformulada, a gente vai entendendo, inventando. Na Serie Abstracto, ela começa com o estudo e a observação de obras visuais com o acompanhamento bibliográfico. Se esse artista escreveu algo, esses escritos têm prioridade. A função da pergunta é nos colocar em relação com o que queremos pesquisar. $\mathrm{O}$ que esse material propõe hoje? A primeira etapa é predominantemente teórica. Depois da pergunta, a gente entra no Laboratório de Estratégias de Encenação, a segunda etapa da metodologia, quando vamos tentar responder de forma prática essa pergunta. E responder como? Procurando procedimentos, procurando mecanismos que possam dar conta, na cena, daquela pergunta que está mexendo com a gente no campo do pensamento e que a gente está elaborando. Esse é um exercício completamente prático e abre caminhos diversos: quando você está pesquisando na cena não é a mesma coisa de quando você está lendo, 
escrevendo, teorizando. Tem o lugar do corpo, tem o lugar das materialidades. O Laboratório de Estratégias de Encenação é o momento em que a gente se debruça sobre a pergunta buscando um caminho para construir a peça final, que seria o segundo momento da metodologia.

David Atencio: No caso de Épico, a ideia de modelamento foi o nosso operador na segunda fase. A gente queria construir uma dramaturgia que fosse como um modelo matemático, como um modelo científico, que permitisse entregar uma chave de leitura no começo para o espectador ir desenvolvendo ao longo da apresentação. Essa foi a nossa estratégia de encenação, uma estratégia complexa porque muito abstrata. Em outros processos a estratégia de encenação é mais evidente ou concreta. A gente fez uma peça que se chamava Tempo, e "temporalizar" era o mecanismo de tornar visível o tempo de forma material. A gente foi criando modos de colocar tempo em tudo. Tinha o cronômetro, tinha o relógio, a partitura. A gente chegou a um espetáculo em que todos os segundos estavam calculados, em que produzíamos a percepção da presença do tempo como material construtor da peça.

Mateus Fávero: A passagem do tempo também foi trabalhada na atuação. Nós, como atores, tínhamos a questão de como materializar o tempo com nossos corpos.

Figura 3 - Tempo (2018), investigação cênica baseada no conceito de construtivismo do russo Vladimir Tatlin (1885-1953).

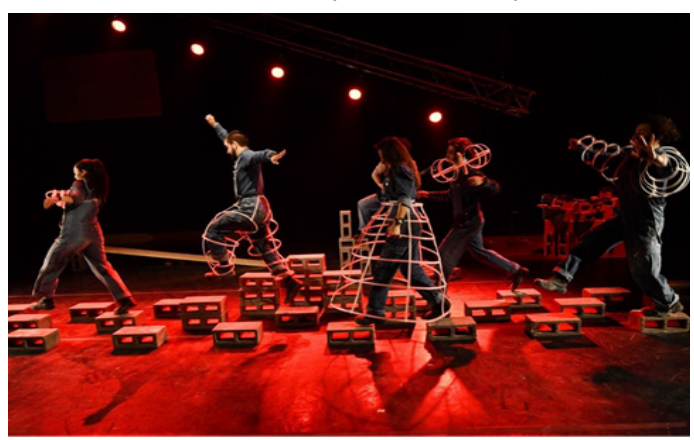

Fonte: Tempo (2018). Foto de Jorge Sánchez (Acervo Tercer Abstracto)
David Atencio: A terceira e última etapa do processo a gente chama de Construção Espaço-Temporal. A pergunta é: como que a gente coloca a nossa pesquisa na experiência do espectador? O espectador não precisa ter lido nada, não precisa ter o nosso conhecimento. Eu não sei onde vai ser o final. Eu só sei onde o espectador vai começar. $E$ a partir disso vamos pensando em fazer o caminhar, como se fosse um corredor, conduzindo o espectador no labirinto. A gente chama de construção espaço-temporal, e não montagem, porque a gente constrói para o espectador.

Rosyane Trotta: Vocês definiram a pergunta e vão iniciar a pesquisa artística. Ainda não existe a dramaturgia, não tem situação, não tem personagem. Que procedimentos vocês usam? Existe alguma divisão de funções criativas nesse momento? Ou cada um faz sua proposta?

David Atencio: A gente vai criando a partir de procedimentos. No caso de Épico, a gente partiu da comparação entre dois contextos: a pandemia atual e a peste na Idade Média. Cada ator foi trazendo algum material, a gente foi escolhendo. Começamos a testar hipóteses. Se a gente imagina um rei que quer que o povo medieval saia de casa, a gente poderia fazer uma aproximação ao Bolsonaro, por exemplo. Como é isso? Alguém pode tentar? A gente testa. Começa sendo um pouco especulativo. O processo vai ser trabalhado a partir de improvisações guiadas pela pergunta. A cena gera uma ideia. Vamos improvisar de novo. Vamos trocar os atores. Vamos buscando modos de investigar a cena.

Mateus Fávero: A gente trabalha muito com improvisação e com propostas dos atores e das atrizes. Em geral não existe a figura de uma dramaturga ou dramaturgo dentro do processo. Somos nós, todos juntos, que vamos criando. Na cena do apartamento, em Épico, eu tinha feito uma proposta, um canovaccio com alguns diálogos. Ao experimentar a cena, eles foram vendo o que faltava, as perspectivas da 
atriz, do ator - e isso foi sendo construído por meio de improvisação, não estava escrito. A dramaturgia na verdade era aquilo que estava acontecendo. Só no final houve um trabalho de formalizar aquilo que tinha sido descoberto pela prática.

David Atencio: Eu experimentei duas realidades diferentes nos processos que realizei no Brasil e no Chile. No Brasil tem uma ideia de workshop: os atores trazem coisas como se fossem peças prontas, com pouco espaço para manejar. Nas equipes chilenas, há preconceito com a palavra improvisação, como se tudo valesse. Nós fazemos uma improvisação estruturada, que se aproxima muito do canovaccio da Commedia dell'Arte: tudo pode acontecer, mas tem que respeitar um monte de regras.

Mateus Fávero: A gente improvisa uma primeira vez. Depois a gente reorganiza em função da pergunta e faz uma segunda improvisação, somando um novo elemento, em geral proposto pelo David. Essas improvisações vão sendo cada vez mais guiadas de acordo com o que estamos pesquisando, o que faz elas irem se estruturando.

David Atencio: No caso de Convenção, a gente queria estabelecer uma relação entre o material e o ideal. A pergunta era "como a gente faz aparecer a materialidade das idealizações?" Com essa pergunta e um monte de leitura, a gente entra em cena.

Mateus Fávero: Em um dos primeiros ensaios, estudando o teatro da convenção consciente, do Meyerhold, a gente entrou em cena com a pergunta "o que é uma convenção". Eu entrei me perguntando: como eu crio uma convenção? Comecei a jogar e começou a aparecer a mímica. Eu não trabalhava com essa técnica, foi a pergunta que pediu.

David Atencio: A gente não tem uma linguagem. Somos um coletivo de pesquisa e vamos buscar as linguagens que se colocam no caminho das nossas pesquisas. Por isso estamos sempre fazendo o que nunca fizemos - teatro de sombras, mímica, vídeo... A forma depende da pergunta, não de um estilo anterior ao processo.

Rosyane Trotta: Há uma continuidade na composição do grupo?

David Atencio: A gente não define a companhia pelas pessoas que formam o grupo, porque de fato as pessoas foram mudando muito. Antes do Tercer Abstracto eu participei de duas companhias. Eu sempre quis continuar um projeto de companhia. Só que depois do segundo fracasso, eu comecei a pensar: essa ideia romântica não corresponde à realidade do século $X X I$, a realidade latino-americana onde a gente trabalha por projeto. Então desde o início nos estruturamos assim. Os elencos se formam mais pelo contexto do momento.

Mateus Fávero: De certo modo a gente tenta manter uma continuidade de grupo, mas entende que nem sempre é possível. Eu briguei muito para a gente ser um coletivo, pra fazer reunião de produção com todo mundo junto. Mas tem gente que não pode, tem outros trabalhos. Como a gente sobrevive fazendo teatro? Eu acho triste que os nossos modos de produção, que os editais não permitam que isso aconteça. Quando a gente foi criar Tempo, queria compor a equipe com quem já tinha trabalhado na companhia, porque a experiência dá uma base. Mas mesmo isso não foi possível, porque a realidade material exigia que as pessoas não pudessem oferecer o tempo de ensaio. A gente, de certo modo, se acostumou com a ideia de trabalhar por projeto. Só que isso também gera contradições.

Rosyane Trotta: Vocês fazem algum tipo de preparação? Como a pessoa se torna um bom parceiro desse projeto? O Mateus Fávero diz: eu entrei em cena só com a pergunta e para procurar o que era convenção. Fico imaginando que é um ator muito específico, esse que se dispõe a entrar em cena com quase nada. 
David Atencio: A gente sempre está refletindo sobre isso. A gente tem oito anos de trabalho. Tem pessoas que já participaram de cinco projetos. Então, sim, tem uma certa repetição. Em Épico, como viemos para o Brasil, teve uma mudança de equipe total. $O$ que $o$ ator, atriz tem que ter? Tem que ter ferramentas de pesquisa, tem que compreender essa política de pesquisar. Ajuda muito ter uma referência de processos anteriores. No Chile acontece muito mais a concepção de ator-intérprete, por exemplo. O nosso ator tem que principalmente gostar de pesquisar e tem que ter ferramentas de diversas áreas para abordar essas perguntas que atravessam o nível entre o artístico e o filosófico muitas vezes.

Mateus Fávero: $O$ ator-pesquisador é uma outra chave. Eu não vou chegar com todas as minhas potencialidades e montar a minha melhor cena. É o oposto, na verdade. Eu vou chegar com o que eu não sei, entrar sem saber o que vem e, aconteça o que acontecer, eu estarei jogando. É pular um pouco no escuro mesmo. Uma atriz nova no grupo disse "eu sinto que estou trabalhando muito mais como filósofa da cena, como dramaturga, do que como atriz". Eu falei "que legal" e ela respondeu "não sei se é tão legal, eu achei que ia trabalhar como atriz". Então existe esse choque do que você espera e do que você está fazendo quando você entra nesse processo.

David Atencio: Mas esse filósofo teatral no fim é o ator ou a atriz. A peça vai sendo feita na medida deles. Eu lembro de um processo em que os atores começaram a trazer exercícios em inglês. Eu não falo em inglês, não entendia nada, e comecei a perceber que todos falavam inglês na minha equipe. Comecei a trabalhar a peça em inglês, eles improvisando e eu não entendendo. Claro que existem esses pulos: vamos construir um teatro de sombras de vinte minutos, então temos que trabalhar nisso, planejar. Essa percepção vem após o laboratório.

Rosyane Trotta: Nessa estruturação metodológica, nessa cronologia de processo, a teoria vem primeiro e depois a prática. É sempre assim?

Mateus Fávero: Essa separação entre teoria e prática é mais para a gente entender do que como ela funciona na verdade. Porque, na verdade, a coisa bonita - ou como eu gosto de ver a pesquisa baseada na prática - é que teoria e prática estão juntas constantemente.

David Atencio: A gente faz uma abertura de processo, no final do laboratório. E temos perguntas muito específicas, para entender como estão funcionando as narrativas, como o espectador percebe. No caso de Tempo, o final do laboratório foi uma performance de três horas no espaço público onde a gente instalou um pequeno cenário e seis atores faziam ações super simples, tipo beber água. A gente se perguntou: "o que aconteceria se a gente ralentasse o tempo?”. Trabalhamos só com o lento - e começou aparecer a tremedeira do corpo e elementos do tempo material. A partir daí entendemos que tínhamos que "temporalizar" tudo. E aí começou o processo final.

Mateus Fávero: Eu chupava um picolé que ia derretendo. A gente lá três horas e as pessoas passando, os carros passando. A gente entendeu que não funcionava como peça. Mas foi a partir dessa ação, como conclusão do laboratório, que a gente entendeu como ia estruturar a peça final, por onde a gente poderia apostar: a ideia da materialidade do tempo.

David Atencio: O laboratório me trouxe o desafio de prender a atenção do espectador a ponto de ele ver essa tremedeira, de materializar esse tempo. Foi uma testagem. Para o espetáculo final, a gente fez uma cena de um minuto e quarenta segundos de imobilidade. 
Mateus Fávero: Isso se reflete na prática da atuação. Para chegar a esse um minuto e quarenta o corpo carregava a história daquelas três horas. $\mathrm{O}$ corpo carrega essa experiência.

Carlos Estranho: Vocês conseguiram materializar o tempo?

David Atencio: Tem várias formas de responder, né? Em termos objetivos, não, porque materializar o tempo não é deter os corpos. Em termos performativos, eu diria que sim, porque o performativo traz esse termo para o experiencial.

Mateus Fávero: Pelos comentários dos espectadores e espectadoras na abertura de processo, se concretiza a materialização do tempo, nesse sentido sensorial. A pessoa entra em uma peça e o que chega para ela é a palavra tempo ou a experiência do tempo, o tempo todo. Eram diversas estratégias para marcar o tempo que estava acontecendo, para dar a ver o tempo acontecendo. Materializar é nossa forma de pensar tempo - não o relógio, que é uma convenção. O que é o tempo? É uma convenção que acontece entre uma coisa e outra. Como a gente materializa isso que a gente não consegue nem ver, nem pensar direito? Foi a nossa aposta de como materializar essa coisa tão abstrata.

David Atencio: Esse um minuto e quarenta em pausa era muito polêmico. Alguns liam como agressivo. A plateia se mexia, se debatia, as cadeiras começavam a ter som. Uma pessoa me disse: de repente o tempo passou pra mim. A gente não disse "perceba o tempo", mas a gente construiu o caminho para a pessoa perceber.

Rosyane Trotta: Como as pesquisas acadêmicas de vocês se relacionam com a pesquisa artística? Ainda se compreende mal a pesquisa em artes cênicas, que se dedica ao processo e se diferencia da pesquisa sobre artes cênicas, que toma a obra concluída. Ainda causa descrença o artista que pesquisa sobre si. Como isso se dá na experiência de vocês?
David Atencio: Todos os nossos projetos acadêmicos têm vínculo direto com a companhia.

Mateus Fávero: Como esse vínculo se estabelece, aí está a questão. O título do meu projeto de mestrado é: Da pergunta à cena: a prática como pesquisa. Eu coloco três abordagens - a pesquisa para as artes, que pesquisa algo que serve à cena; a pesquisa sobre as artes, que é o estudo de uma cena que já aconteceu; a pesquisa em artes, que é do que estamos falando, pesquisar na cena. Isso é muito difícil de ser aceito dentro das universidades. É uma luta constante. Essa discussão começa muito forte depois do Tratado de Bolonha, nos anos 1990, que reformula a educação e unifica os mestrados e doutorados na Europa. No Brasil, o Zamboni (2001), quando está criando a área de Artes dentro do CNPq, traz essa concepção da pesquisa em artes. Em seguida ele faz um doutorado e publica a tese no livro Pesquisa em Artes, um paralelo entre arte e ciência. Nas Artes Visuais da USP, você pode concluir o mestrado ou o doutorado com uma obra e ela é entendida como resultado da sua pesquisa. Nas artes cênicas você também pode fazer, mas tem que apresentar um material teórico, que é como acontece no Chile também. Mas lá eles compreendem que, sim, o seu resultado é a cena e não aquele texto, que é um complemento, uma memória da pesquisa. $\mathrm{Na}$ USP, eu sinto que se valida mais o material teórico. $\mathrm{O}$ que eu procuro no meu mestrado é cavar um pouco mais esse caminho. Mas eu estou no campo teórico, isso é uma contradição. Eu estudo três companhias que praticam a investigação, uma delas é o Tercer Abstracto.

David Atencio: No Chile tudo é pago, não há mestrados nem graduações gratuitas. As universidades públicas também são pagas. Eu tive uma bolsa para o mestrado e meu trabalho foi abordar a metodologia da Tercer Abstracto a partir da criação de uma peça com a companhia e da construção da memória desse processo. No doutorado, minha proposta era trabaIhar com as vanguardas artísticas, por meio de sete 
laboratórios, cada laboratório dedicado a um desses movimentos. O objetivo final da pesquisa seria investigar a metodologia do laboratório como pedagogia de formação de artistas. O primeiro laboratório seria sobre a Bauhaus ${ }^{3}$. Com a pandemia tive que repensar o projeto. Schlemmer ${ }^{4}$ propõe uma metodologia de trabalho super esquemática - o estudo do gesto, da linha, da cor, do espaço, de cada elemento compositivo - que sugere uma cena científica. $E$ isso me parece uma característica do pensamento moderno. Então o novo projeto é sobre arte e ciência: estou estudando a passagem do século XIX para o XX, entendendo como a física do eletromagnetismo começou a empregar procedimentos abstratos. E estou propondo que o meu trabalho cênico se dê a partir de modelos. Por exemplo as maquetes, não como representação realista, mas como estrutura.

Rosyane Trotta: Há algum registro sobre esse processo?

David Atencio: Se vocês têm interesse nessa relação entre arte e ciência, podem acessar no site ${ }^{5}$ a peça Azul ${ }^{6}$, de 2020. A gente fez o projeto para um edital de criação e para um edital de pesquisa. E a gente só ganhou o de pesquisa. Então a peça virou um processo de pesquisa. A gente estudou o imaterialismo e o resultado final foi uma peça imaterial. Nela há um documentário ${ }^{7}$ em que a gente registrou todo o processo. Ele tem uma hora e meia, e é resultado e processo, pesquisa e obra, ao mesmo tempo.

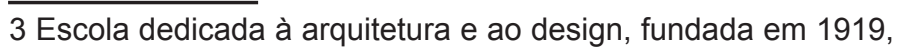
na Alemanha, por Walter Gropius.

4 Artista e professor da Bauhaus, foi o principal mentor da pedagogia teatral da escola.

5 https://tercerabstracto.com/.

6 Sétimo espetáculo do grupo, a obra investiga o imaterialismo a partir de Yves Klein (1928-1962), pintor e fotógrafo francês.

7 "Azul, documental de proceso (2020)", publicado em 26 de janeiro, disponível em https://www.youtube.com/watch?v=qeGzghPvCXY. Acesso em: 29 set. 2021.
Figura 4 - Azul (2020), investigação cênica baseada no imaterialismo do artista francês Yves Klein (1928-1962).

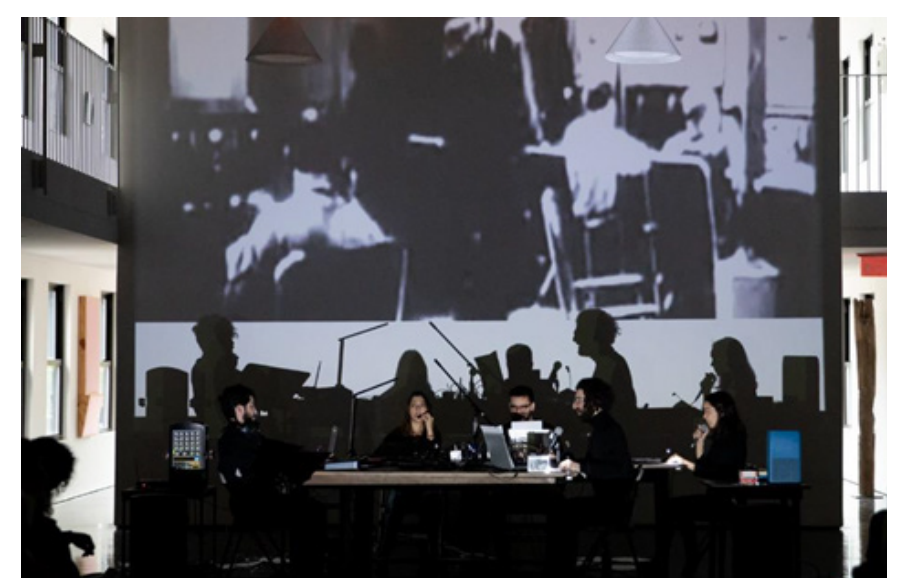

Fonte: Azul (2020). Foto de Watermill Center (Acervo Tercer Abstracto)

Grassi Santana: Na universidade às vezes é angustiante a segmentação, a excessiva especialização, a noção de que para gerar algo consequente a gente tem que escolher um caminho muito específico e permanecer nele. A fala de vocês me traz uma percepção diferente, de que o não saber move. A gente pode ter uma metodologia que leve a caminhos não fechados.

David Atencio: Eu vejo uma diferença entre estudar, pesquisar e experimentar. A gente estuda as coisas que são conhecidas e que estão nos livros, nas bibliografias. Ou como fazer um bolo - a gente estuda para fazer. Experimentar é fazer trocas dentro desse sistema de coisas conhecidas, por exemplo: o que seria fazer um bolo sem ovos. Aí eu começo a experimentar possibilidades. Uma pesquisa inclui estudo e experimentação.

Mateus Fávero: Pesquisar, para mim, é buscar o conhecimento pelo não saber - isso faz com que desapareça a questão da especialização. As três companhias que eu estudei no mestrado têm essa característica: não estão trabalhando uma linguagem ou formas ou formatos específicos. Elas estão 
trabalhando uma pergunta, uma grande pergunta que a cada processo é uma outra pergunta. A forma vem como resultado da pesquisa, não é o ponto de partida.

Figura 5 - Teorema (2016), investigação cênica a partir de estudo sobre a arte do russo Wassily Kandinsky (1866-1944) e a teoria do caos no campo das matemáticas.

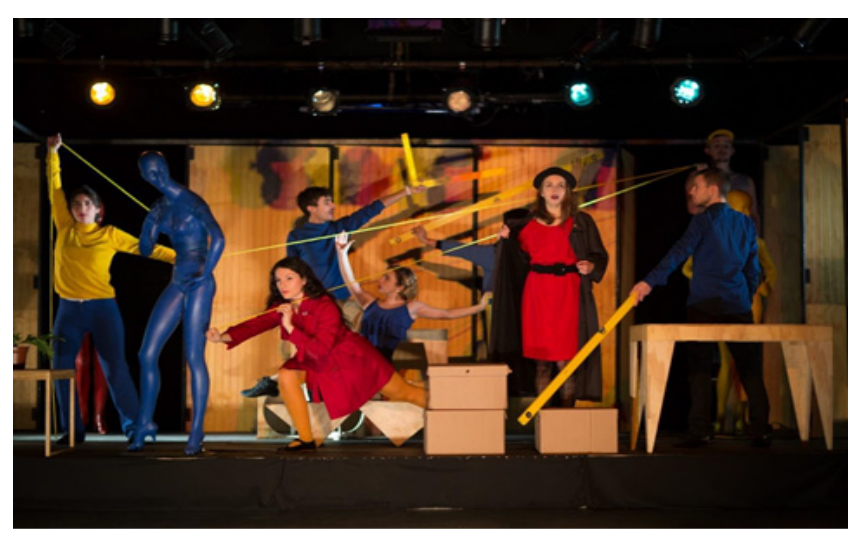

Fonte: Teorema (2016). Foto de Juan Ramírez. (Acervo Tercer Abstracto)

\section{Referências}

BORGDORFF, Henk. El debate sobre la investigación en las artes. Cairon: Revista de Ciencias de la Danza, Alcalá de Henares: Servicio de Publicaciones de la Universidad de Alcalá, n. 13, p. 25-46, 2010.

- ¿Dónde estamos hoy? El estado del arte en la investigación artística. Entre Diálogos, v. 3, n. 3, p. 102-113, novembro, 2017.

CONTRERAS, Maria José. La práctica artística en la formación de postgrado: Polémicas, transferencias y diálogos. In: MUNDIM, Ana Carolina et al (Eds.). Múltiplos olhares sobre processos descoloniais nas artes cênicas. São Paulo: Paco editorial, p. 93- 113, 2018.

. La práctica como investigación: Nuevas Me- todologías para la Academia Latinoamericana. Poiésis. Niterói, n. 21-22, p. 71-86, jul./dez., 2013.

ARJ, Art Research Journal / Revista de Pesquisa em Artes, v. 1, números 1 e 2, 2014. Disponível em https://periodicos.ufrn.br/artresearchjournal/issue/ view/353 e https://periodicos.ufrn.br/artresearchjournal/issue/view/354. Acesso em: 30 set. 2021.

HASEMAN, Brad. Manifesto pela pesquisa performativa. In.: Seminários de Pesquisas em Andamento PPGAC/USP, v. 5., 2015, São Paulo. Resumos. São Paulo: SiBi/USP, p. 41-53, 2015. Disponível em:

https://files.cercomp.ufg.br/weby/up/378/o/Manifesto_pela_pesquisa_performativa_\%28Brad_Haseman\%29.pdf. Acesso em: 30 set. 2021.

RAMOS, Luiz Fernando. Pesquisa Performativa: Uma tendência a ser bem discutida. In. Seminários de Pesquisas em Andamento PPGAC/USP, 5., 2015, São Paulo. Resumos. São Paulo: SiBi/USP, 2015. Disponível em:

http://www3.eca.usp.br/sites/default/files/form/biblioteca/acervo/producao-academica/002732339.pdf. Acesso em: 30 set. 2021.

(org). Arte e ciência: abismo sobre rosas. São Paulo: ABRACE, p. 256, 2012. Disponível em: http:// portalabrace.org/impressos/2_arte_e_ciencia_abismo_de_rosas.pdf. Acesso em: 30 set. 2021.

ROYO, Victória Pérez; SÁNCHEZ, José Antonio. La Investigación en Artes Escénicas: introducción. Cairon: Revista de Ciencias de la Danza, Alcalá de Henares: Servicio de Publicaciones de la Universidad de Alcalá, n. 13, p. 05-14, 2010.

SÁNCHEZ, José Antonio. Investigación y experiencia. Metodologías de la investigación creativa en artes escénicas. Estudis Escénics. Quaderns del'Institut del Teatre. Barcelona, n. 35, p. 327-335, 2009.

ZAMBONI, Silvio. A pesquisa em Arte: um paralelo 
entre arte e ciência. Campinas: Editores Associados, 2001.

Recebido: 28/03/2021

Aceito: $24 / 09 / 2021$

Aprovado para publicação: 29/10/2021

Este é um artigo de acesso aberto distribuído sob os termos de uma Licença Creative Commons Atribuição 4.0 Internacional. Disponível em: http://creativecommons.org/licenses/by/4.0.

This is an open-access article distributed under the terms of the Creative Commons Attribution License 4.0 International. Available at: http://creativecommons.org/licenses/by/4.0.

Ce texte en libre accès est placé sous licence Creative Commons Attribution 4.0 International. Disponible sur: http://creativecommons.org/licenses/by/4.0.

hronicle, v. 6, n. 1, p. 79-83, 1982. 